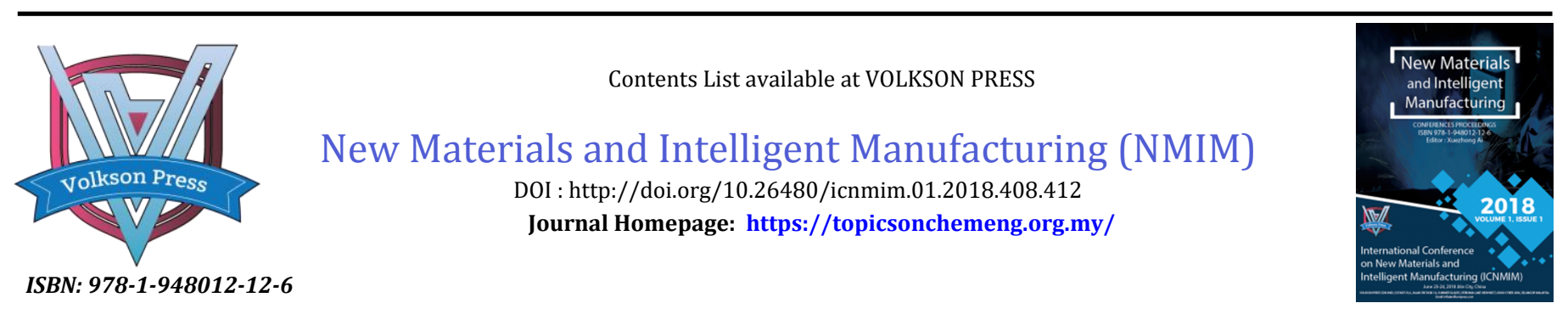

\title{
STUDY ON THE EXTRACTION OF PIGMENT FROM FRUIT OF ROSA DAVURICA PALL.WITH MICROWAVE COENZYME METHOD AND ITS STABILITY AND INOXIDIZABILITY
}

\author{
Di Song, Lei Yong-ping, Zhong Fang-li*, Wang Xiao-lin, YinJia-mian

\begin{abstract}
School of Chemistry and Pharmaceutical Engineering, Jilin Institute of Chemical Technology, Chengde Street, Jilin, China *Corresponding Author E-mail: fanglizhong@sina.com
\end{abstract}

This is an open access article distributed ader the Creative Commons Attribution License, which permits unrestricted use, distribution, and reproduction in any medium, provided the original work is properly cited.

\section{ARTICLE DETAILS}

\section{Article History:}

Received 26 June 2018 Accepted 2 July 2018 Available online 1 August 2018

\section{ABSTRACT}

To explore the best extracting process, stability and antioxidation activity in vitro of pigment extracted from fruit of Rosa davurica Pall., orthogonal design method was applied to determine optimal results. Antioxidant ability of pigment can be determined by its scavenging activity and reducing power to $\mathrm{DPPH}$, $\mathrm{NaNO}_{2}$. The stability of pigment was tested using UV-Vis spectrophotometry. The best process to extract pigment was as follows, methyl alcohol (50\%) was used as extractant. The complex phosphoesterasum was used as enzymes type formed by cellulase and pectinase. Enzyme dosage was equal to $1.2 \%$ of quality of dry fruit of Rosa davurica Pal.l (FRDP). Solidliquid ratio was selected as 1:30 and microwave power was $600 \mathrm{~W}$. The extraction was conducted in the solution with pH 6.0 for 17 minutes at $65^{\circ} \mathrm{C}$. The stability testing showed that pigment was not stable in the alkaline solution with $\mathrm{Fe}^{3+}$. Other factors had poor effect on stability of pigment. The antioxidant ability of pigment was confirmed by anti-oxidative experiment.

\section{KEYWORDS}

Fruit of Rosa davurica Pall, microwave coenzyme, pigment, antioxidant.

\begin{abstract}
1. INTRODUCTION
Based on a study, FRDP belongs to Rosa of Rosaceae and is a kind of dried dahurian rose fruit whose active constituents include flavonoid, organic acid, coumarins and polyphenols [1-3]. Research showed it is expected to be fully exploited and utilized [4]. According to the previous study, pigments of plant possess a strong oxidative resistance, which can help prevent cancer, protect the skin and improve body immunity [5]. Being safe and reliable without other side-effect are feature of natural pigments. Besides, natural coloring gives it an important role in food additives $[6,7]$. Therefore, with the developing of food industry, natural pigments will be highly valued which will replace of artificial pigments $[8,9]$.
\end{abstract}

The traditional method to extract pigment will consume a mass of solvent, which takes a long time but has a poor effect. According to a research, with the advantages of high efficiency, simplicity of operator, high yield and the easily purified product, microwave coenzyme will be widely used in extraction of natural pigment [10-12]. Enzyme will break the cell wall of FRDP, which can promote the extraction of effective constituent. Microwave coenzyme was used to extract pigment in the test. At the same time, the stability and oxidative resistance of pigment were study in the research which will lay a solid foundation on the further study.

\section{MATERIALS AND METHODS}

\subsection{Materials and reagents}

FRDP was picked from Jade Dragon Mountain in LongTan district, JiLin City and was authenticated by Dr.JianfeiXue of pharmacy department of JiLin Instituite of Chemical Technology as a kind of dried dahurian rose fruit in Botanical hillbelongs to Rosa of Rosaceae. The rest of reagents are all analytical reagentsor food additives.

\subsection{Instruments and equipments}

Ultravioletand visible spectrophotomer(TU-1810), thermostat water bath(W5-100SP), electronicanalytical balance (FA2004N), SHZ-IIID(SHBIIIA), electric heating air-blowing drier(DHG-9076A), supersonic cleaner(KQ118), microwave extractor(MAS-II).

\subsection{Experimental methods}

\subsubsection{Extraction of pigment}

According to the result of single factor experiment, the fixed extractant was based of $50 \%$ methyl alcohol. The complex phosphoesterasum which was formed by cellulase and pectinase was used as enzymes type. The experiment was based on 5 factors: Dosage of enzyme, solid-liquid ratio, microwave power, extraction duration and extraction temperature. Orthogonal experiment is designed on the base of five factors and four levels. The factors and levels of orthogonal experiment were shown in Table 1. 
Table 1: Orthogonal experiment and its level

\begin{tabular}{|llllll|}
\hline item & $\begin{array}{l}\text { dosage } \\
\text { enzyme A }\end{array}$ & $\begin{array}{l}\text { of } \\
\text { B solid-liquid ratio }\end{array}$ & $\begin{array}{l}\text { microwave } \\
\text { power C }\end{array}$ & duration D/min & $\begin{array}{l}\text { temperature } \\
\mathrm{E} /{ }^{\circ} \mathrm{C}\end{array}$ \\
\hline 1 & $1.0 \%$ & $1: 15$ & 400 & 13 & 55 \\
2 & $1.2 \%$ & $1: 20$ & 500 & 15 & 60 \\
3 & $1.4 \%$ & $1: 25$ & 600 & 17 & 65 \\
4 & $1.6 \%$ & $1: 30$ & 700 & 20 & 70 \\
\hline
\end{tabular}

\subsubsection{Investigation of pigment stability}

The changes in the absorbance of pigment are measured under $370 \mathrm{~nm}$. Besides, effect of $\mathrm{pH}$ value, temperature, illumination, citric acid, vitamin $\mathrm{C}$, sodium benzoate, oxidizing agent, metal ion, glucose and starch on pigment stability were researched.

\subsubsection{Vitro antioxidant experiments}

\section{(1) Scavenging activity on DPPH}

Refer to research of Fan [13] with some adjustments, $2 \mathrm{~mL}$ of samples with different concentration for mass respectively were putinto $10 \mathrm{~mL}$ colorimetric tube before $2 \mathrm{~mL}$ liquor of $0.2 \mathrm{mmol} / \mathrm{L} \mathrm{DPPH}$ added in. After mixing, the mixture was placeed in dark before used for reaction at room temperature for $30 \mathrm{~min}$. The sample of blank group was replaced by distilled water. Besides, DPPH. was replaced by ethyl alcohol and distilled water was taken as a reference. Absorbance of sample A, blank A and reference A were investigated under a wave length of $517 \mathrm{~nm}$.

DPPH clearance rate\% $\%[($ blankA -sampleA+reference A)/blank A $] \times 100$

which blankA is $2 \mathrm{~mL}$ DHHP. added with $2 \mathrm{~mL}$ water, reference A is $2 \mathrm{~mL}$ absolute ethyl alcohol added with $2 \mathrm{~mL}$ water, sampleA is $2 \mathrm{~mL} \mathrm{DPPH}$. added with $2 \mathrm{~mL}$ sample for test.

(2) Measurement of reducing power

Referring to research, with some improvements, $1 \mathrm{~mL}$ of fluid with different concentration of mass were put into $2.5 \mathrm{~mL}$ of phosphate buffer $(0.2 \mathrm{~mol} / \mathrm{L}, \mathrm{PH}=6.6)$ and $2.5 \mathrm{~mL}$ of $1 \%$ aqueous solution of potassium ferricyanide, respectively [14]. After mixing and cooling in thermostatic water bath at $50{ }^{\circ} \mathrm{C}$ for $20 \mathrm{~min}, 1 \mathrm{~mL}$ of solution for trichloroacetic acid $(10 \%)$ was put into the mixture before centrifuged for $10 \mathrm{~min}$ at 500 r/min. $2.5 \mathrm{~mL}$ of supernate was put into another test tube firstly. Then 2.5 $\mathrm{mL}$ of distilled water and $0.5 \mathrm{~mL}$ of liquor ferritrichloridi $(0.1 \%)$ were added in before mixed and stood for 10 min. Absorbance A was measured under $700 \mathrm{~nm}$ with ethanol solution $(50 \%)$ to be blank contral. Solution of sample will not be added into the blank group, which can carry out a measurement of absorbance $\mathrm{A}_{0}$.

Pigment reduction force $=\mathrm{A}-\mathrm{A}_{0}$

(3) Elimination to nitrite

Based on a study, with some adjustments, $1 \mathrm{~mL}$ of fluid to be checked with different concentration of mass were taken before $2.5 \mathrm{~mL}$ of solution of $\mathrm{NaNO}_{2}(10 \mu \mathrm{g} / \mathrm{mL})$ added in [15]. Then the reaction was carried out in thermostatic waterbath at $37^{\circ} \mathrm{C}$ for $30 \mathrm{~min}$. After the above operations, 0.5 $\mathrm{mL}$ of solution of sulfanilic acid $(0.4 \%)$ was added in immediately. Then $0.25 \mathrm{~mL}$ of $0.2 \%$ solution of Naphthalene hydrolorideis added in after mixing and standing for $15 \mathrm{~min}$. Finally, $7 \mathrm{~mL}$ of distilled water was added in before mixed and stood for $15 \mathrm{~min}$. With $50 \%$ ethyl alcohol used to be blank control, the absorbance value $A_{i}$ is measured under $538 \mathrm{~nm}$.

Nitrite clarity rate $\%=\left[\left(A_{0}-A_{i}+A_{j}\right) / A_{0}\right] \times 100$

which $A_{i}$ is meant for absorbance of fluid under test, $A_{j}$ is meant for test solution background value, $A_{0}$ is meant for comparison with no fluid under test.

\section{RESULT AND DISCUSSION}

\subsection{The result of orthogonal experiment}

16 portions of dry FRDP were weighed and taken for each $2.0 \mathrm{~g}$. The conditions of extraction were made according to the table of orthogonal test. After the extraction, enzyme was killed in condition of $90^{\circ} \mathrm{C}$ for $30 \mathrm{~s}$ before filtrated with filter liquor which diluted by $50 \%$ methyl alcohol before constant volume. The absorbance was measured under $370 \mathrm{~nm}$. The result was shown in Table 2 .

Table 2: The result and analysis of orthogonal experiment

\begin{tabular}{|c|c|c|c|c|c|c|}
\hline $\begin{array}{l}\text { Experiment } \\
\text { number }\end{array}$ & A & B & $\mathrm{C}$ & $\mathrm{D}$ & $\mathrm{E}$ & absorbance \\
\hline 1 & 1 & 1 & 1 & 1 & 1 & 0.462 \\
\hline 2 & 1 & 2 & 2 & 2 & 2 & 0.467 \\
\hline 3 & 1 & 3 & 3 & 3 & 3 & 0.473 \\
\hline 4 & 1 & 4 & 4 & 4 & 4 & 0.468 \\
\hline 5 & 2 & 1 & 2 & 3 & 4 & 0.466 \\
\hline 6 & 2 & 2 & 1 & 4 & 3 & 0.468 \\
\hline 7 & 2 & 3 & 4 & 1 & 2 & 0.467 \\
\hline 8 & 2 & 4 & 3 & 2 & 1 & 0.471 \\
\hline 9 & 3 & 1 & 3 & 4 & 2 & 0.447 \\
\hline 10 & 3 & 2 & 4 & 3 & 1 & 0.447 \\
\hline 11 & 3 & 3 & 1 & 2 & 4 & 0.447 \\
\hline 12 & 3 & 4 & 2 & 1 & 3 & 0.449 \\
\hline 13 & 4 & 1 & 4 & 2 & 3 & 0.447 \\
\hline 14 & 4 & 2 & 3 & 1 & 4 & 0.444 \\
\hline 15 & 4 & 3 & 2 & 4 & 1 & 0.448 \\
\hline 16 & 4 & 4 & 1 & 3 & 2 & 0.449 \\
\hline $\mathrm{K}_{1}$ & 0.4675 & 0.4555 & 0.4565 & 0.4555 & 0.457 & \\
\hline $\mathrm{K}_{2}$ & 0.468 & 0.4565 & 0.4575 & 0.458 & 0.4575 & \\
\hline $\mathrm{K}_{3}$ & 0.4475 & 0.45875 & 0.45875 & 0.45875 & 0.45925 & \\
\hline $\mathrm{K}_{4}$ & 0.447 & 0.45925 & 0.45725 & 0.45775 & 0.45625 & \\
\hline $\mathrm{R}$ & 0.021 & 0.00375 & 0.00225 & 0.00325 & 0.003 & \\
\hline
\end{tabular}


According to the results in Table 2, the order of effects of factors on the extraction for pigment was $A>B>D>E>C$. Therefore, it could be summarized that proper dosage of compound of enzyme has the greatest effect to extraction followed by solid-liquid ratio, extracting time, extracting temperature in turns. Finally, microwave power has the poorest impact to extraction. After comprehensive analysis, the best condition for extraction were $\mathrm{A}_{2} \mathrm{~B}_{4} \mathrm{C}_{3} \mathrm{D}_{3} \mathrm{E}_{3}$. In summary, the dosage of compound of enzyme was $1.2 \%$ of quality for FRDP. Solid-liquid ratio was selected as 1:30. Microwave power was selected to be $600 \mathrm{~W}$. Time for extraction was $17 \mathrm{~min}$ and extracting temperature was $65^{\circ} \mathrm{C}$. The type of enzyme was a compound enzyme which is made of cellulose and pectase.

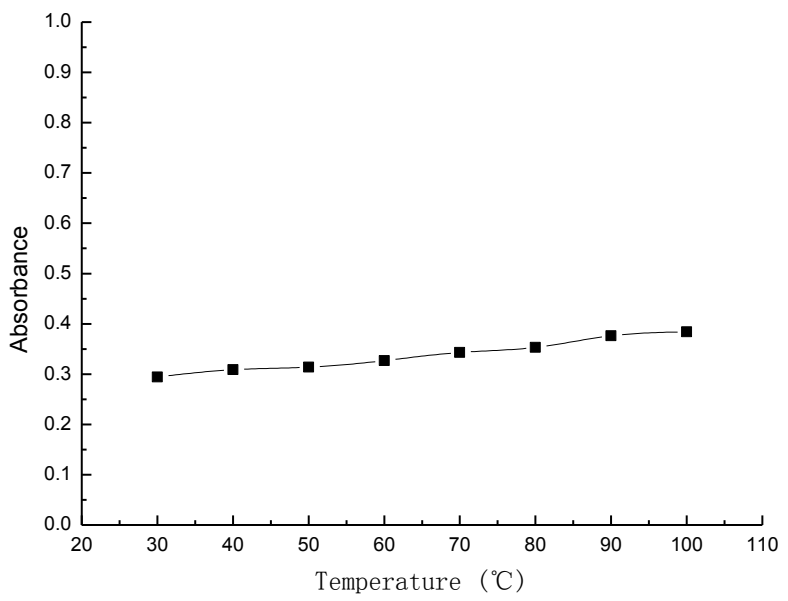

Figure 1: The effect of $\mathrm{pH}$ value on pigment stability

\subsubsection{The effect of temperature on pigment stability}

The extracting solution for pigment in section 2.2.1 were transferred into water bath kettle at $30,40,50,60,70,80,90,100{ }^{\circ} \mathrm{C}$ respectively. The result was shown in Figure 2 that temperature for extraction had a certain effect on stability of pigment.

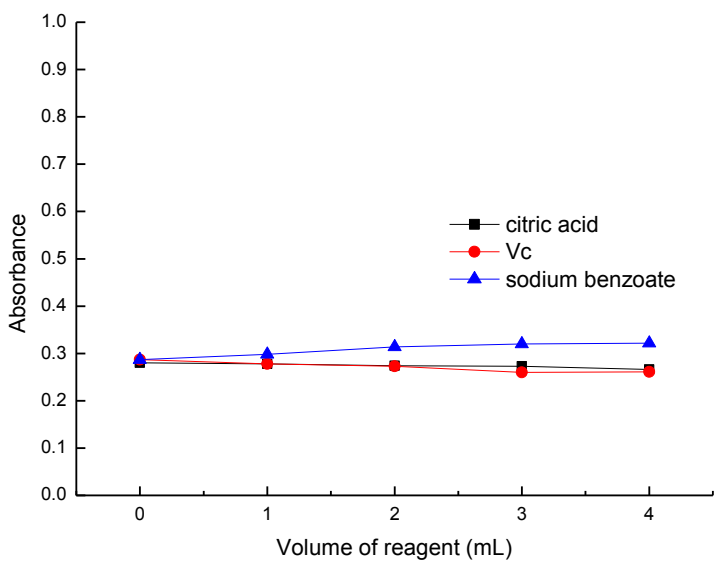

Figure 3: The effect of citric acid, Vc, sodium benzoate on pigment stability

\subsubsection{The effect of oxidizing agent on pigment stability}

As shown in Figure 4, the addition of hydrogen peroxide changed the absorbance of pigment a little, which explained the poor effect of oxidizing agent on stability pigment.

\subsection{Test of pigment stability}

\subsubsection{The effect of temperature on pigment stability}

As shown in Figure 1, the extracted solution of pigment remained stable in the condition of $\mathrm{pH}=2 \sim 6$. The stability of pigment performs poor when $\mathrm{pH}$ value was above 7 . It was obvious in the experiment that solution of extraction for pigment appeared orange in acidic condition. While it appeared red orange in neutrality condition and presents tangerine in alkaline condition.

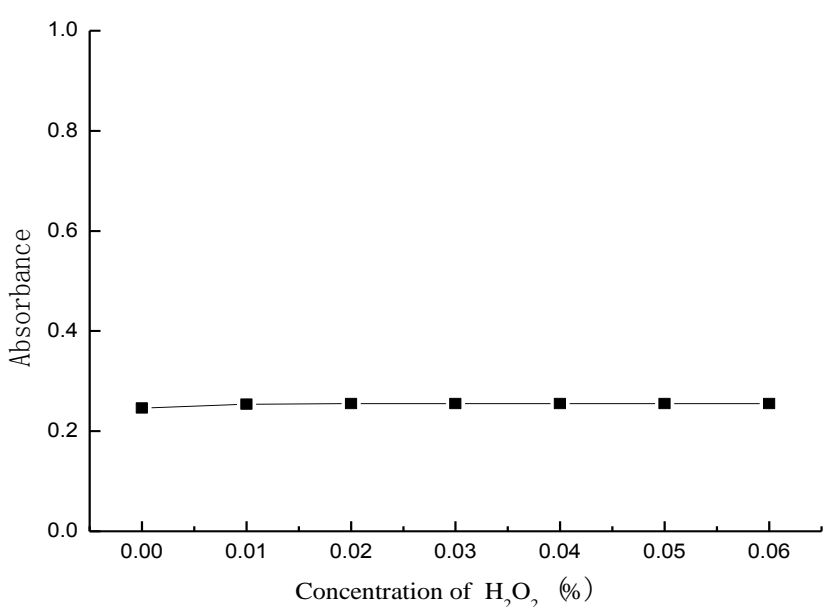

Figure 2: The effect of temperature on pigment stability

\subsubsection{The effect of citric acid, Vc, sodium benzoate on pigment stability}

The result was shown in Figure 3. With the increase of added citric acid, $\mathrm{Vc}$ and sodium benzoate, the absorbance of pigment tended to be stable, which explained the poor effect of citric acid, Vc sodium benzoate on pigment stability

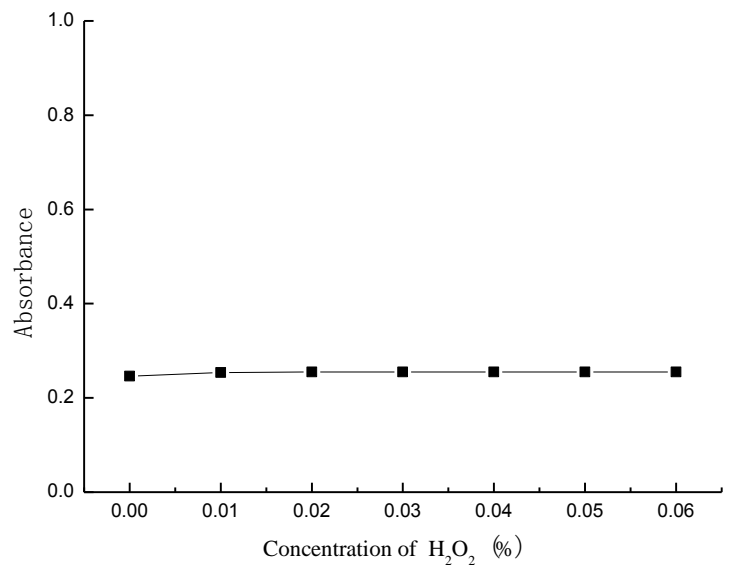

Figure 4: The effect of oxidizing agent on pigment stability

\subsubsection{The effect of glucose on pigment stability}

The result was shown in Figure 5. With the addition of glucose solution in different concentration, the curve appeared stable as a whole, which explained glucose had no effect on pigment stability. 


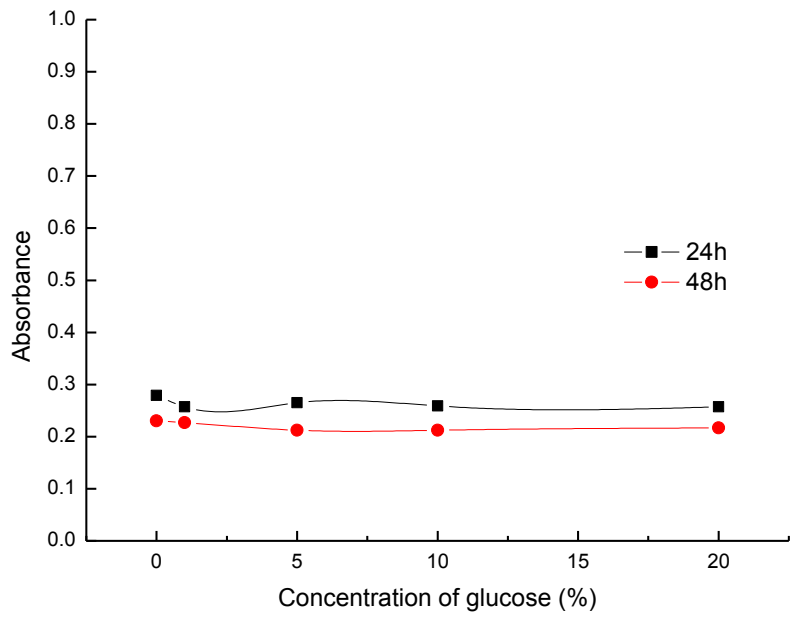

Figure 5: The effect of glucose on pigment stability

\subsubsection{The effect of starch on pigment stability}

The result was shown in Figure 6. With the addition of starch solution in different concentration, the curve appeared stable as a whole. Ignoring the experimental error, starch had no effect on pigment stability.

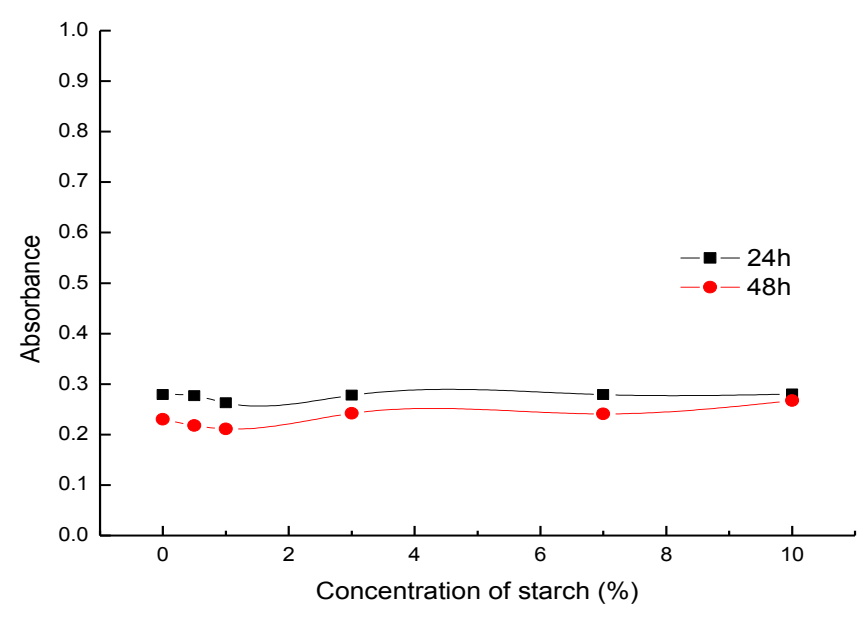

Figure 6: The effect of starch on pigment stability

\subsubsection{The effect of illumination on pigment stability}

All the experiments were conducted in room temperature. The result was shown in Table 3. The absorbance of pigment had a little change with different strength of illumination, which explained its poor effect.

Table 3: The effect of illumination on pigment stability

\begin{tabular}{|lllll|}
\hline illumination & indoor light & sunlight & UV-light & $\begin{array}{l}\text { place away } \\
\text { from sunlight }\end{array}$ \\
\hline absorbance & 0.286 & 0.288 & 0.297 & 0.319 \\
\hline
\end{tabular}

\subsubsection{The effect of metal ion on pigment stability}

The result was shown in Table 4. The addition of solution of sodium cholride, calciumcholride and maganesium sulfate did not change the absorbance for pigment obviously. While it benefiteda lot from the ferric tricholride. That meant $\mathrm{Na}^{+}, \mathrm{Ca}^{2+}$ and $\mathrm{Mg}^{2+}$ had little effect on stability of pigment of pigment, while $\mathrm{Fe}^{3+}$ had a relativelylarger impact.

Table 4: The effect of metal ion on pigment stability

\begin{tabular}{|lcccccc|}
\hline $\begin{array}{l}0.01 \quad \text { mol/L } \\
\text { solution }\end{array}$ & metalion & blank & $\begin{array}{l}\text { sodium } \\
\text { cholride }\end{array}$ & $\begin{array}{l}\text { calcium } \\
\text { cholride }\end{array}$ & $\begin{array}{l}\text { maganesiu } \\
\text { m sulfate }\end{array}$ & $\begin{array}{l}\text { ferric } \\
\text { tricholride }\end{array}$ \\
\hline $24 \mathrm{~h}$ & 0.279 & 0.259 & 0.272 & 0.284 & 2.171 \\
$48 \mathrm{~h}$ & 0.230 & 0.212 & 0.236 & 0.226 & 2.052 \\
\hline
\end{tabular}

\subsection{In Vitro Antioxidant Experiment of Pigment}

As shown in Figure 7, the clearance rate to DPPH. increased up to about $90 \%$ with the growing of concentration of mass when concentration of pigment ranged from $0.01 \mathrm{mg} / \mathrm{mL}$ to $0.1 \mathrm{mg} / \mathrm{mL}$. When concentration of pigment was over $0.1 \mathrm{mg} / \mathrm{mL}$, the increase of concentration of pigment had almost no influence on the clearance rate to DPPH. With the growing concentration of pigment, clearance to nitrite for pigment increased. This positive correlation indicated that pigment had a certain clearance to nitrite. According to Figure 8, the curve tended to rise when the concentration of pigment of samples increased, which indicated that reducing capacity of pigment gained when the concentration increases. 


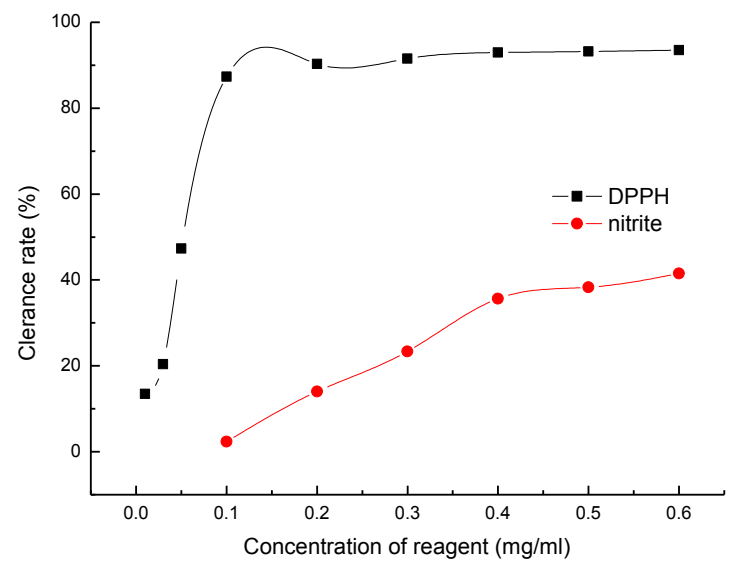

Figure 7: The measurement of pigment antioxidant capacity

\section{CONCLUSION}

Using FRDP as raw material, microwave coenzyme was applied to extract pigment. The best extracting process was determined by orthogonal design and single factor experiment. With the stability and inoxidizability of pigment be explored, the best method to extract pigment was as follows:50\% methyl alcohol was used as extractant. The complex phosphoesterasum formed by cellulase and pectinase was used as type of enzymes. Dosage of enzyme was based of $1.2 \%$ quality of dry FRDP and solid-liquid ratio was selected as 1:30. Microwave power was $600 \mathrm{~W}$ and $\mathrm{pH}=6.0$. The process of extraction was carried out at $65^{\circ} \mathrm{C}$ for $17 \mathrm{~min}$. The pigment was stable under acidic condition and illumination, temperature, oxidizing agent, citric acid, Vc, sodium benzoate, dextrose solution, starch solution had almost no effect on the stability. $\mathrm{Na}^{+}, \mathrm{Ca}^{2+}, \mathrm{Mg}^{2+}$ had a small impact on the stability of pigment. While $\mathrm{Fe}^{3+}$ had a big influence on stability. Pigment possesses a certain clearance to $\mathrm{DPPH}$ and nitrite, besides, it possessed strong reducing capacity. This indicated that pigment had a certain in vitro oxidation resistance, which with the increase growth of concentration of mass for pigment. Pigment is a kind of natural pigment with high economic value and was expected to be exploited. It can be widely used in the development of healthy food and drinking. However, the specific functions need further exploration.

\section{REFERENCES}

[1] Wang, L.D., Li, Y.R., Pan, H.F. 2012. The test of in Fruit of Rosa davurica Pall from different areas. Journal of Chengde Medical College, 29 (1), 5.

[2] Yu, X.J., Yu, X.L. 2000. The extraction process of total flavonoid content in Fruit of Rosa davurica Pall in orthogonal test. Journal of Heilongjiang traditional Chinese medicine, 39 (1), 46.

[3] Cheng, D.Y., Wang, L.S., Fan, Y.J. 2011. The study of total flavonoid purification process in Fruit of Rosa davurica Pall. Journal of Lishizhen Medical Material Medical Research, 22 (3), 664.

[4] Zhong, F.L., Chen, S., Guan, X.X. 2010. The study of applying microwave method to extract total flavonoid in Fruit of Rosa davurica Pall. Journal of Jiangsu Agricultural Sciences, (6), 449-451.

[5] Huang, Y.L., Pang, Z.C., Chen, X.F. 2009. The extract pigment of grape skin and its stability research. Journal of the food research and development, 30 (10), 159-163.

[6] Zhi, Z.Q. 2015. The study of applying microwave method to extract HaiNan fruit acuminatissima pigment. Journal of Chinese Condiment, 40 (2), 110-113.

[7] Zhang, G.D., Qiu, X.D., Hu, B. 2014. The study of stability and process optimization of mulberry red extraction by microwave method. Journal of Chinese Food Addition, (6), 107-111.

[8] Li, H.L., Liu, K.D., Yuan, C.C. 2014. Extraction process optimization of red meat pitaya fruit pigment and its antioxidant activity. Journal of Food and fermentation industry, 40 (12), 203-209.

[9] Wu, J.J., Mei, G., Yu, B. 2015. The process study of applying microwave

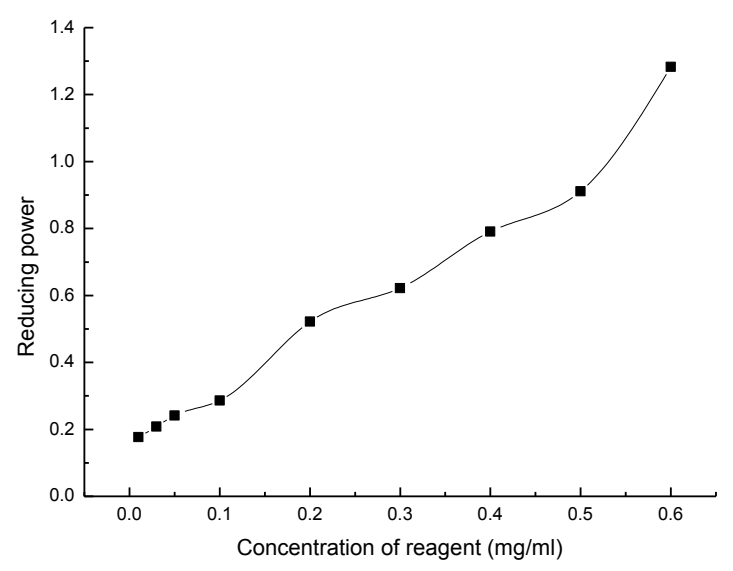

Figure 8: The measurement of pigment reducing capacity

method to extracting red date red pigment. Journal of the study and development of food, 36 (3), 43-46.

[10] Huang, Q., Chen, C., Peng, H. 2010. The process study of applying microwave method to extracting purple sweet potato skin procyanidin. Journal of Food Science, 35 (4), 199-203.

[11] Wen, C.J., Chen, X.G., Rao, F. 2011. The process study of applying microwave method to extracting grenadine. Journal of Food and mechanical engineering, 27 (6), 103 -106.

[12] Liu, X.L., Zhong, S.S., Yu, G.P. 2012. The study of applying microwave method and water distillation to extract clove. Journal of Food and mechanical engineering, 28 (4), 110-112.

[13] Ylan, J.F., Zhang, Z.Q., Fan, Z.C. 2008. Antioxidant effects and cytotoxicity of three purified polysaccharides from Ligusticumchuanxiong Hort. Journal of Carbohydrate Polymers, 74 (4), 822-827.

[14] Fan, Y.J., He, X.J., Zhol, S.D. 2009. Composition analysis and antioxidant activity of polysaccharide from Dendrobiumdenneanum. Journal of International Journal of Biological Macramolecules, 45 (2), 169-173.

[15] Chang, L.X., Zhang, L.F., Du, M.Y. 2005. The study of rose pigment stability and its scavenging activity to nitrite. Journal of Food science, 26 (7), 99-101. 